\title{
Eupatilin inhibits the proliferation of human esophageal cancer TE1 cells by targeting the Akt-GSK3及 and MAPK/ERK signaling cascades
}

\author{
XIAONA WANG ${ }^{1-3^{*}}$, YANYAN ZHU ${ }^{1,3,4^{*}}$, LILI ZHU ${ }^{1,3}$, XINHUAN CHEN $^{1,3}$, YANYAN XU ${ }^{1,3}$, YAFEI ZHAO ${ }^{1}$, \\ YINGZHE SHAO $^{1}$, FENG LI ${ }^{1,3}$, YANAN JIANG ${ }^{1,3}$, JING LU ${ }^{1,3}$, YOUTIAN HUANG ${ }^{1}$, XIAOBIN CHANG ${ }^{1,2}$, \\ JUAN ZHANG $^{1,5}$, XIANG LI ${ }^{1,3}$, KANGDONG LIU ${ }^{1,3,6}$, MINGYAO ZHAO ${ }^{1}$, ZIMING DONG ${ }^{1,3}$ and JIMIN ZHAO $^{1,3}$ \\ ${ }^{1}$ Department of Pathophysiology, School of Basic Medical Sciences, Zhengzhou University, Zhengzhou, \\ Henan 450001; ${ }^{2}$ Sanquan College of Xinxiang Medical University, Xinxiang, Henan 453000; \\ ${ }^{3}$ Henan Provincial Cooperative Innovation Center for Cancer Chemoprevention, Zhengzhou, Henan 450000; \\ ${ }^{4}$ Department of Biochemistry and Molecular Biology, School of Basic Medical Sciences, \\ Zhengzhou University, ${ }^{5}$ Zhengzhou Central Hospital, Zhengzhou, Henan 450001; \\ ${ }^{6}$ China-US (Henan) Hormel Cancer Institute, Zhengzhou, Henan 450000, P.R. China
}

Received September 13, 2017; Accepted March 30, 2018

DOI: $10.3892 /$ or.2018.6390

\begin{abstract}
Eupatilin, a type of flavonoid compound, has potential anti-inflammatory and antitumor roles in gastric cancer and endometrial cancer; however, the effect of eupatilin on human esophageal cancer and the underlying molecular mechanisms remain unclear. In the present study, we investigated the antitumor effect of eupatilin on human esophageal cancer cells in vitro and in vivo. We found that eupatilin inhibited the proliferation and colony formation of esophageal cancer TE1 cells. DNA content analysis showed that eupatilin induced cell cycle arrest of TE1 cells at the $\mathrm{G}_{0} / \mathrm{G}_{1}$ phase. In addition, our results suggested that eupatilin suppressed TE1 cell proliferation by targeting the Akt/GSK3 $\beta$ and MAPK/ERK signaling cascades. Furthermore, treatment with eupatilin was found to decrease tumor volume in a TE1 xenograft mouse model, and the phosphorylation of Akt and ERK1/2 was inhibited by eupatilin in the tumor tissue. Notably, no obvious weight loss for the mice was detected. In conclusion, the present results indicate that the antiproliferative effect of eupatilin on esophageal cancer TE1 cells is associated with inhibition of the Akt and ERK pathways.
\end{abstract}

Correspondence to: Dr Jimin Zhao or Dr Ziming Dong, Department of Pathophysiology, School of Basic Medical Sciences, Zhengzhou University, 100 Science Avenue, Zhengzhou, Henan 450001, P.R. China E-mail: zhaojimin@zzu.edu.cn

E-mail: dongzm@zzu.edu.cn

${ }^{*}$ Contributed equally

Key words: eupatilin, esophageal cancer, Akt-GSK3 $\beta$, MAPK/ERK, TE1 cells

\section{Introduction}

Esophageal carcinoma is among the common types of malignant tumors to develop in humans, and is classified into two pathological types, namely esophageal squamous cell carcinoma (ESCC) and esophageal adenocarcinoma. Approximately $70 \%$ of ESCC cases in the world occur in China (1). The identification of novel low-toxic therapeutic agents is urgently required for the prevention and treatment of ESCC.

Natural plant ingredients or small synthetic molecules are currently a topic of focus in the field of cancer prevention and treatment. Flavonoids are polyphenols widely found in a variety of edible plants, and have been shown to have antioxidative, anti-inflammatory and antitumor activities in both in vivo and in vitro systems (2-4). Specifically, their antitumor effects include inhibition of cell proliferation and promotion of apoptosis in vitro $(5,6)$. Various flavonoids have been reported to serve as cancer chemopreventive agents that exert protective effects against cancer development (5). Eupatilin is a type of antitumorigenic flavonoid component, with the molecular structure 5,7-dihydroxy-3',4',6-trimethoxyflavone, as shown in Fig. 1A. It has been found that eupatilin has anti-inflammatory and antitumor effects (6-10), but the underlying mechanisms remain unclear.

Several signaling pathways that regulate cell proliferation and survival have been implicated as therapeutic targets in cancer in preclinical and clinical trials (11). The Ras signaling pathway, principally consisting of Ras, Raf, MEK and MAPK kinase/extracellular signal-regulated kinase (ERK), plays a significant role in the regulation of cell proliferation through its influence on growth factors (12-14). Uncontrolled Ras signaling has been related to the development of many human cancers (15-17). Furthermore, MAPK activation often leads to the growth or metastasis of tumors. 
Additionally, abnormal activation of the PI3K/Akt signaling pathway has been reported in several types of human cancers, and its activation results in cancer development, namely by influencing tumor cell proliferation, growth, angiogenesis and survival (18). Moreover, the Akt signal pathway may play an important role in cell cycle control by targeting cyclin D1, which is also regulated by Ras-dependent signaling (19-22). Thus, the MEK/ERK and PI3K/Akt pathways may co-regulate cyclin D1 to affect cell cycling.

Researchers have found that the targets of many flavonoid compounds are involved in multiple signaling pathways, including the Ras/Raf/MEK/MAPK and $\mathrm{PI} 3 \mathrm{~K} / \mathrm{Akt} / \mathrm{PTEN} / \mathrm{mTOR}$ pathways $(11,23)$. In the present study, we evaluated the inhibitory effects of the flavonoid compound eupatilin on human esophageal cancer cells. The results showed that eupatilin inhibited the proliferation of esophageal cancer TE1 cells, decreased anchorage-independent growth of the cells, and induced $\mathrm{G}_{0} / \mathrm{G}_{1}$ phase cell cycle arrest. Furthermore, our results indicated that eupatilin suppressed TE1 cell proliferation by targeting the Akt/GSK3 $\beta$ and MAPK/ERK signaling cascades. We also found that eupatilin decreased tumor volume in a TE1 xenograft mouse model, while the body weights of all mice remained stable after eupatilin treatment. Additionally, Ki-67 expression and the phosphorylation of Akt and ERK1/2 were suppressed by eupatilin in the xenograft tumors. Overall, our results indicate that the antiproliferative effect of eupatilin on esophageal cancer TE1 cells is at least in part associated with inhibition of the Akt and ERK pathways.

\section{Materials and methods}

Cell culture and chemicals. The human esophageal cancer cell line TE1 was cultured in Dulbecco's modified Eagle's medium (DMEM), which contained $10 \%$ fetal bovine serum (FBS), streptomycin $(100 \mathrm{U} / \mathrm{ml})$ and penicillin $(100 \mathrm{U} / \mathrm{ml})$, at $37^{\circ} \mathrm{C}$ in a $5 \% \mathrm{CO}_{2}$ saturated humidity incubator. Eupatilin was supplied by Chunqiu (Nanjing, China) and dissolved in dimethyl sulfoxide (DMSO). The primary antibodies were purchased from the Cell Signaling Technology, Inc. (Danvers, MA, USA) and Santa Cruz Biotechnology, Inc. (Dallas, TX, USA). The secondary antibodies were purchased from Santa Cruz Biotechnology, Inc. PD98059 (MEK inhibitor) and LY294002 (PI3K inhibitor) were obtained from Beyotime Institute of Biotechnology (Shanghai, China).

Determination of cell viability. We used the Cell Counting Kit-8 (CCK-8; KeyGen Biotech Co., Ltd., Nanjing, China) method to detect the toxicity of eupatilin in TE1 cells. TE1 cells $\left(1 \times 10^{4}\right)$ were plated into the wells of 96 -well plates. When the cells were adhered to the bottom of the wells, the medium was replaced with medium containing different concentrations of eupatilin $(0,2.5,5,10,20$ or $40 \mu \mathrm{M})$. After 24 and $48 \mathrm{~h}$ of incubation, $10 \mu \mathrm{l}$ of CCK-8 solution was added and the cells were incubated for $2 \mathrm{~h}$ in a $\mathrm{CO}_{2}$ incubator. Subsequently, cell absorbance was measured with a microplate reader (Bio-Rad Laboratories, Inc., Hercules, CA, USA) at $450 \mathrm{~nm}$. The results were calculated as mean and standard deviation, and are expressed as a percentage reduction for the eupatilin-treated group, assuming that the absorbance of the control cells was $100 \%$.
Cell proliferation assay. The esophageal cancer TE1 cells $\left(3 \times 10^{3}\right)$ were transferred into the wells of 96 -well plates in $200 \mu \mathrm{l}$ culture medium and incubated for 6-8 h until the cells were adhered to the wells. The medium was then replaced with medium containing eupatilin at the indicated doses $(0,2.5,5$, 10, 20 or $40 \mu \mathrm{M}), 20 \mu \mathrm{M}$ PD98059 or $20 \mu \mathrm{M}$ LY294002. The treated cells were cultured for $0,24,48,72$ or $96 \mathrm{~h}$. Subsequently, $10 \mu \mathrm{l}$ of CCK-8 solution was added to each well, and after a 2-h incubation in $\mathrm{a} \mathrm{CO}_{2}$ incubator, the optical densities of the wells at $450 \mathrm{~nm}$ were measured with a microplate reader.

Anchorage-independent cell growth assay. A volume of $3 \mathrm{ml}$ basal medium eagle (BME) (Sigma-Aldrich; Merck KGaA, Darmstadt, Germany) including $10 \%$ FBS and $0.5 \%$ agarose was spread in the wells of 6-well plates, to which different concentrations of eupatilin, $20 \mu \mathrm{M}$ PD98059 or $20 \mu \mathrm{M}$ LY294002 were added before the mixture became solidified. TE1 cells were then suspended at a density of $8 \times 10^{3}$ cells in $1 \mathrm{ml} \mathrm{BME}(10 \% \mathrm{FBS}$ and $0.33 \%$ agarose) with the indicated concentrations of eupatilin $(0,2.5,5,10,20$ or $40 \mu \mathrm{M}), 20 \mu \mathrm{M}$ PD98059 or $20 \mu \mathrm{M}$ LY294002, and the mixture was seeded onto the top of the agarose layer in each well of the 6-well plates. The cells were cultured in $\mathrm{a} \mathrm{C}_{2}$ incubator, and we observed and calculated the colony number in each well on the 14 th day of culture.

Cell cycle assay by flow cytometry. TE1 cells were treated with different concentrations of eupatilin, $20 \mu \mathrm{M}$ PD98059 or $20 \mu \mathrm{M}$ LY294002 for $24 \mathrm{~h}$. The cells were then trypsinized and washed twice with cold phosphate-buffered saline (PBS). Subsequently, the cells were fixed with $70 \%$ ethyl alcohol, then stored at $4^{\circ} \mathrm{C}$ until use. To evaluate cell cycle distribution, the stored cells were washed twice with PBS and incubated with $50 \mu \mathrm{g} / \mathrm{ml} \mathrm{RNase} \mathrm{A}$ for $2 \mathrm{~h}$ at $37^{\circ} \mathrm{C}$. The cells were then stained with $50 \mu \mathrm{g} / \mathrm{ml}$ propidium iodide for $30 \mathrm{~min}$ in the dark at room temperature. Following staining, the DNA contents of the cells $\left(1 \times 10^{4}\right)$ was analyzed with a FACSCalibur flow cytometer and CellQuest analysis software (BD Biosciences, Franklin Lakes, NJ, USA).

Western blot analysis. TE1 cells were treated with different concentrations of eupatilin, $20 \mu \mathrm{M}$ PD98059 or $20 \mu \mathrm{M}$ LY294002 for $24 \mathrm{~h}$, after which total cell protein was isolated using RIPA lysis buffer (50 mM Tris-base, 1\% NP-40, $0.25 \%$ SOD, $150 \mathrm{mM} \mathrm{NaCl}, 1 \mathrm{mM}$ EDTA, $0.1 \%$ SDS, $1 \mathrm{mM} \mathrm{Na} \mathrm{VO}_{4}$, $1 \mathrm{mM} \mathrm{NaF}, 1 \mathrm{mM}$ PMSF and $10 \mu \mathrm{l}$ protease inhibitor). The protein concentration of the supernatant was measured using a protein assay kit (Beyotime Institute of Biotechnology) with a microplate reader. Subsequently, $50 \mu \mathrm{g}$ of protein, dissolved in lysis buffer, was separated on a $10 \%$ SDS-PAGE gel and transferred to polyvinylidene difluoride (PVDF) membranes. The membranes were blocked with $5 \%$ non-fat milk-TBST buffer (TBS containing $0.1 \%$ Tween-20) for $2 \mathrm{~h}$ at room temperature. After blocking, the PVDF membranes were incubated with primary antibodies against Akt (1:1,000 dilution; cat. no. 2938s; Cell Signaling Technology, Inc.), GSK3 $\beta$ (1:1,000 dilution; cat. no. 9315; Cell Signaling Technology, Inc.), CREB (1:1,000 dilution; cat. no. 9197; Cell Signaling Technology, Inc.), ERK1/2 (1:1,000 dilution; cat. no. 4695; Cell Signaling Technology, Inc.), phospho-Akt (Ser473) 
(1:500 dilution; cat. no. 4060; Cell Signaling Technology, Inc.), phospho-GSK3 $\beta$ (Ser9) (1:1,000 dilution; cat. no. 9336; Cell Signaling Technology, Inc.), phospho-CREB (Ser133) (1:1,000 dilution; cat. no. 9191; Cell Signaling Technology, Inc.) and phospho-ERK1/2 (Thr202/Tyr204) (1:1,000 dilution; cat. no. 9102; Cell Signaling Technology, Inc.) overnight at $4{ }^{\circ} \mathrm{C}$. Equal protein loading was compared using $\alpha$-tubulin antibody (1:1,000 dilution; Santa Cruz Biotechnology, Inc.). The membrane was washed 3 times with TBST buffer for 10 min per wash, then incubated with HRP-IgG secondary antibody (1:200 dilution; Santa Cruz Biotechnology, Inc.) for $4 \mathrm{~h}$ at $4^{\circ} \mathrm{C}$. Following washing of the membrane 3 times for $10 \mathrm{~min}$ each, the transferred proteins were detected as protein bands using chemiluminescence reagent with an ImageQuant LAS 4000 imager (GE Healthcare, Chicago, IL, USA).

In vivo tumor growth assay. All animal studies conformed to guidelines approved by the Research Ethics Committee of Zhengzhou University. Athymic nude mice (BALB/c nude mice, female, 4-6 weeks old) were purchased from Vital River Laboratory Animal Technology Co., Ltd. (Beijing, China). The animals were kept at $23-25^{\circ} \mathrm{C}$ under a 12 -h light/dark cycle and administered sterile water and food ad libitum. After 1 week of adaptation, TE1 cells $\left(1 \times 10^{7}\right.$ in $\left.0.1 \mathrm{ml}\right)$ were subcutaneously inoculated into the right flank of each mouse. Animals were randomly divided into the following 3 groups $(n=5$ mice per group): Vehicle group; $10 \mathrm{mg} / \mathrm{kg}$ eupatilin-treated group; and $50 \mathrm{mg} / \mathrm{kg}$ eupatilin-treated group. The mice were administered eupatilin ( 10 or $50 \mathrm{mg} / \mathrm{kg}$ body weight in $1 \mu \mathrm{l}$ of DMSO as vehicle) or vehicle alone 3 times/week by intraperitoneal injection. Mice were weighed and tumor size was measured with a caliper 3 times/week. Tumor volume was calculated from cross-sectional measurements of the individual tumor based on the following formula: Tumor volume $\left(\mathrm{mm}^{3}\right)=($ length $\mathrm{x}$ width $\mathrm{x}$ width/2). Mice were monitored until day 36 , after which the mice were euthanized and the tumors were extracted.

Hematoxylin and eosin staining. All acquired tumor tissues were subject to hematoxylin and eosin (H\&E) staining. Tumor tissues were fixed with $10 \%$ formalin and embedded in paraffin, and $4-\mu \mathrm{m}$-thick specimen sections were prepared on glass slides. The sections were deparaffinized in xylene and rehydrated with graded alcohol, then stained with H\&E and scanned using TissueFAXS (TissueGnostics GmbH, Vienna, Austria).

Immunohistochemical staining. Tumor tissues were fixed with $10 \%$ formalin and embedded in paraffin, and $4-\mu \mathrm{m}$-thick specimen sections were prepared on glass slides. The sections were deparaffinized in xylene and rehydrated with graded alcohol, then soaked with $0.3 \%$ hydrogen peroxide $\left(\mathrm{H}_{2} \mathrm{O}_{2}\right)$ for $5 \mathrm{~min}$. Antigen retrieval was performed in sodium citrate buffer (pH 6.0) with a microwave. Subsequently, the sections were incubated with antibodies against Ki-67 (ZM-0165) (1:50 dilution; Zhongshan Jinqiao Biotechnology Co., Ltd., Beijing, China), p-Akt (Ser473) (1:50 dilution; cat. no. 4060; Cell Signaling Technology, Inc.), p-ERK1/2 (Thr202/Tyr204) (1:100 dilution; cat. no. 9102; Cell Signaling Technology, Inc.) at $4^{\circ} \mathrm{C}$ overnight, then with HRP-conjugated secondary antibody (ZSGB-BIO, Beijing, China) at $37^{\circ} \mathrm{C}$ for $20 \mathrm{~min}$.
The peroxidase reaction was visualized by incubating the sections with 2,4-diaminobenzidine substrate. After rinsing in water, the sections were counterstained with hematoxylin, then dehydrated with graded alcohol and cover slipped. All of the sections were scanned using TissueFAXS analyzed using HistoQuest 4.0 software (both from TissueGnostics $\mathrm{GmbH}$ ) and evaluated using the H-Score system.

Statistical analysis. All quantitative data are expressed as the mean \pm standard deviation. Multi-group comparisons of the means were carried out by one-way analysis of variance (ANOVA) test with posthoc contrasts by Student-Newman-Keuls test. ANOVA and Student's t-test were used for statistical analysis using SPSS 22.0 software (IBM Corp., Armonk, NY, USA). The sample sizes were chosen to allow for statistical significance testing assuming a major effect and a small variation. A value of $\mathrm{P}<0.05$ was considered to indicate statistical significance.

\section{Results}

Eupatilin inhibits the proliferation of TE1 cells. Eupatilin is a type of flavonoid and exhibits anti-inflammatory and antitumor effects. To evaluate the effect of eupatilin on the proliferation of human esophageal cancer TE1 cells, the cytotoxic effect of eupatilin on TE1 cells was measured by CCK-8 assay. TE1 cells were treated with different concentrations of eupatilin $(3.125,6.25,12.5,25$ or $50 \mu \mathrm{M})$ for 24 and $48 \mathrm{~h}$. The results showed that the percentage of viable TE1 cells was reduced to $60 \%$ following treatment with $50 \mu \mathrm{M}$ eupatilin for $48 \mathrm{~h}$ (Fig. 1B). Following treatment of TE1 cells with these concentrations of eupatilin $(2.5,5,10,20$ or $40 \mu \mathrm{M})$ for different time periods $(0,24,48,72$ or $96 \mathrm{~h})$, the cell growth curve indicated that eupatilin inhibited TE1 cell proliferation in concentration-dependent and time-dependent manners (Fig. 1C). The concentration of the drug tested in the study was selected according to the cytotoxicity of eupatilin shown in Fig. 1B. The results showed that the percentage of viable TE1 cells was reduced to $80 \%$ following treatment with $3.125 \mu \mathrm{M}$ eupatilin for $48 \mathrm{~h}$, which indicated that eupatilin has a significant antiproliferation effect on human esophageal cancer at low concentrations. When the concentration of eupatilin was $50 \mu \mathrm{M}$, the cell viability was $60 \%$ for $48 \mathrm{~h}$ (Fig. 1B). Therefore, concentrations of eupatilin from 2.5 to $40 \mu \mathrm{M}$ were used for subsequent experiments.

Eupatilin suppresses the anchorage-independent growth of TE1 cells. To determine whether eupatilin inhibits the anchorage-independent growth of TE1 cells, we observed cell colony number in a soft agar assay after a 14-day culture. The results indicated that eupatilin inhibited the colony formation capacity of TE1 cells dose-dependently compared with the DMSO controls (Fig. 1D and E). Additionally, MEK and PI3K inhibitors, PD98059 and LY294002 respectively, were also observed to inhibit TE1 colony formation in the assay.

Eupatilin induces cell cycle arrest at $G_{0} / G_{I}$ phase. To evaluate whether the inhibitory effect of eupatilin on cell proliferation was related to induction of cell cycle arrest, further experiments were performed in TE1 cells. TE1 cells were treated with different 
A

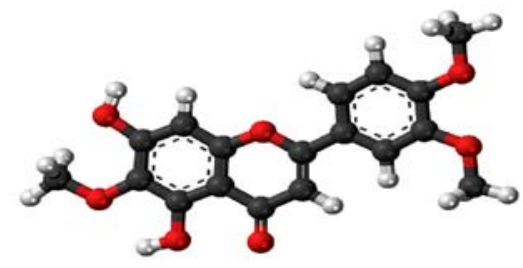

C

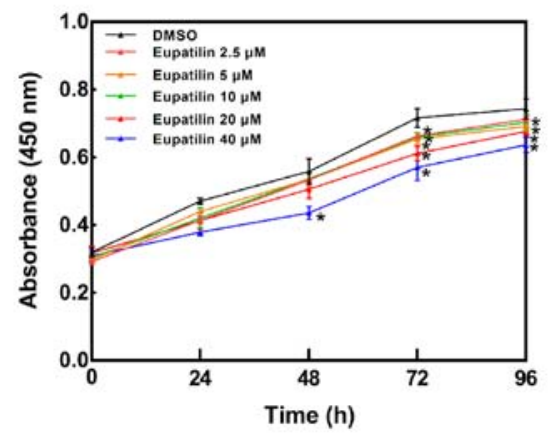

$\mathbf{E}$

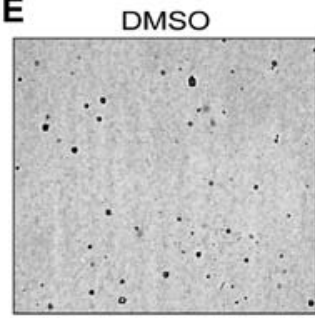

Eupatilin $20 \mu \mathrm{M}$

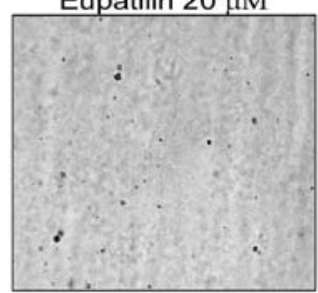

Eupatilin $2.5 \mu \mathrm{M}$

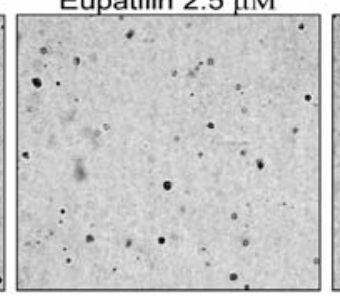

Eupatilin $40 \mu \mathrm{M}$

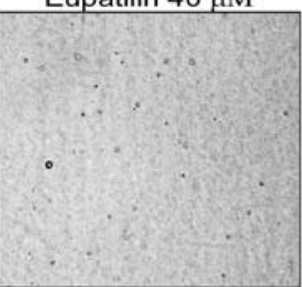

B
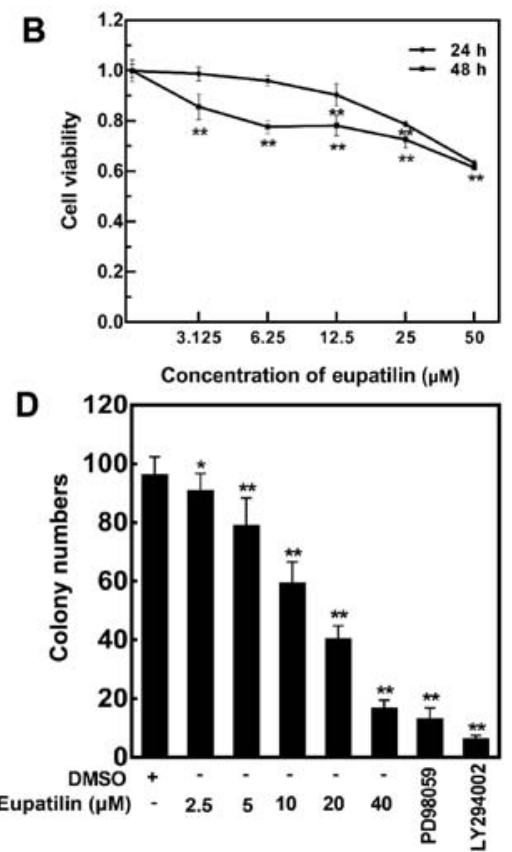

Eupatilin $5 \mu \mathrm{M}$

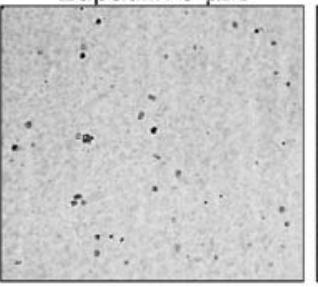

PD98059 $20 \mu \mathrm{M}$

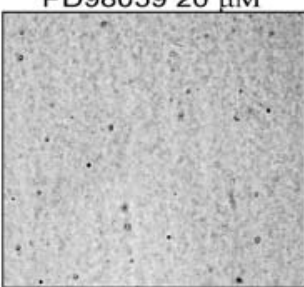

Eupatilin $10 \mu \mathrm{M}$

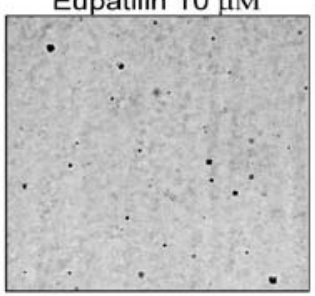

LY294002 $20 \mu \mathrm{M}$

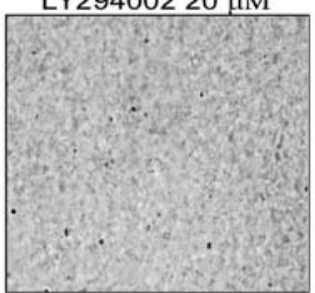

Figure 1. Eupatilin inhibits the proliferation and anchorage-independent growth of esophageal cancer TE1 cells. (A) Chemical structure of eupatilin (5,7-dihydroxy-3',4',6-trimethoxyflavone). Color code: carbon, black; hydrogen, white; oxygen, red. (B) The viability of TE1 cells was detected by Cell Counting Kit-8 (CCK-8) assay. TE1 cells were treated With the indicated doses of eupatilin for 24 and $48 \mathrm{~h}$. Data are presented as mean values \pm SD from triplicate experiments. Statistical significance was determined by Student's t-test ( ${ }^{* *} \mathrm{P}<0.01$ vs. DMSO control). (C) Proliferation inhibition effect of eupatilin on TE1 cells. TE1 cells were treated with different concentrations of eupatilin for $0,24,48,72$ or $96 \mathrm{~h}$, and the absorbance of cells was assessed using a CCK- 8 assay. Data are presented as mean values \pm SD from triplicate experiments (" $\mathrm{P}<0.05$ vs. DMSO control). (D and E) Inhibitory effect of eupatilin on the colony formation capacity of TE1 cells. Cells were treated with the indicated concentrations of eupatilin with or without $20 \mu \mathrm{M}$ PD98059 or $20 \mu \mathrm{M}$ LY 294002. Images were captured using a microscope (magnification, $\mathrm{x} 4$ ). Representative images are shown and data are presented as mean values \pm SD from triplicate experiments. As shown by the statistical results of the colony assay, eupatilin obviously reduced the number and size of the TE1 colonies compared with the DMSO control ( $\left(\mathrm{P}<0.05\right.$ and $\left.{ }^{* *} \mathrm{P}<0.01\right)$.

concentrations of eupatilin $(0,2.5,5,10,20$ or $40 \mu \mathrm{M}), 20 \mu \mathrm{M}$ PD98059 or $20 \mu \mathrm{M}$ LY294002 for $24 \mathrm{~h}$, and the distribution of cells in the different phases of the cell cycle was analyzed by flow cytometry. We found that there was an accumulation of cells in the $\mathrm{G}_{0} / \mathrm{G}_{1}$ phase when the cells were treated with eupatilin (Fig. 2). Similar changes also occurred in the PD98059- and LY294002-treated groups. These results of flow cytometry indicated that eupatilin induced $\mathrm{G}_{0} / \mathrm{G}_{1}$ arrest in the TE1 cells.

Eupatilin regulates the signaling pathways of $A k t / G S K 3 \beta / C R E B$ and MAPK/ERK. To further explore the molecular mechanism underlying the inhibitory effect of eupatilin on TE1 cell proliferation, we detected the expression of key molecules in the Akt/GSK3 $\beta$ and MAPK/ERK pathways. We observed that the treatments with different concentrations of eupatilin in TE1 cells for $24 \mathrm{~h}$ caused significant decreases in the levels of p-Akt, p-GSK3 $\beta$, p-CREB (Fig. 3A) and p-ERK (Fig. 3B). Similar effects were also observed following treatment with PD98059 or LY294002. These data indicated that eupatilin inhibited TE1 cell proliferation by regulating the signaling pathways of Akt/GSK3 $\beta$ and MAPK/ERK.

Eupatilin suppresses tumor growth in a xenograft mouse model. To further investigate whether eupatilin could suppress tumor growth in vivo, we evaluated the antitumor activity of eupatilin in athymic nude mice implanted with TE1 cells. 


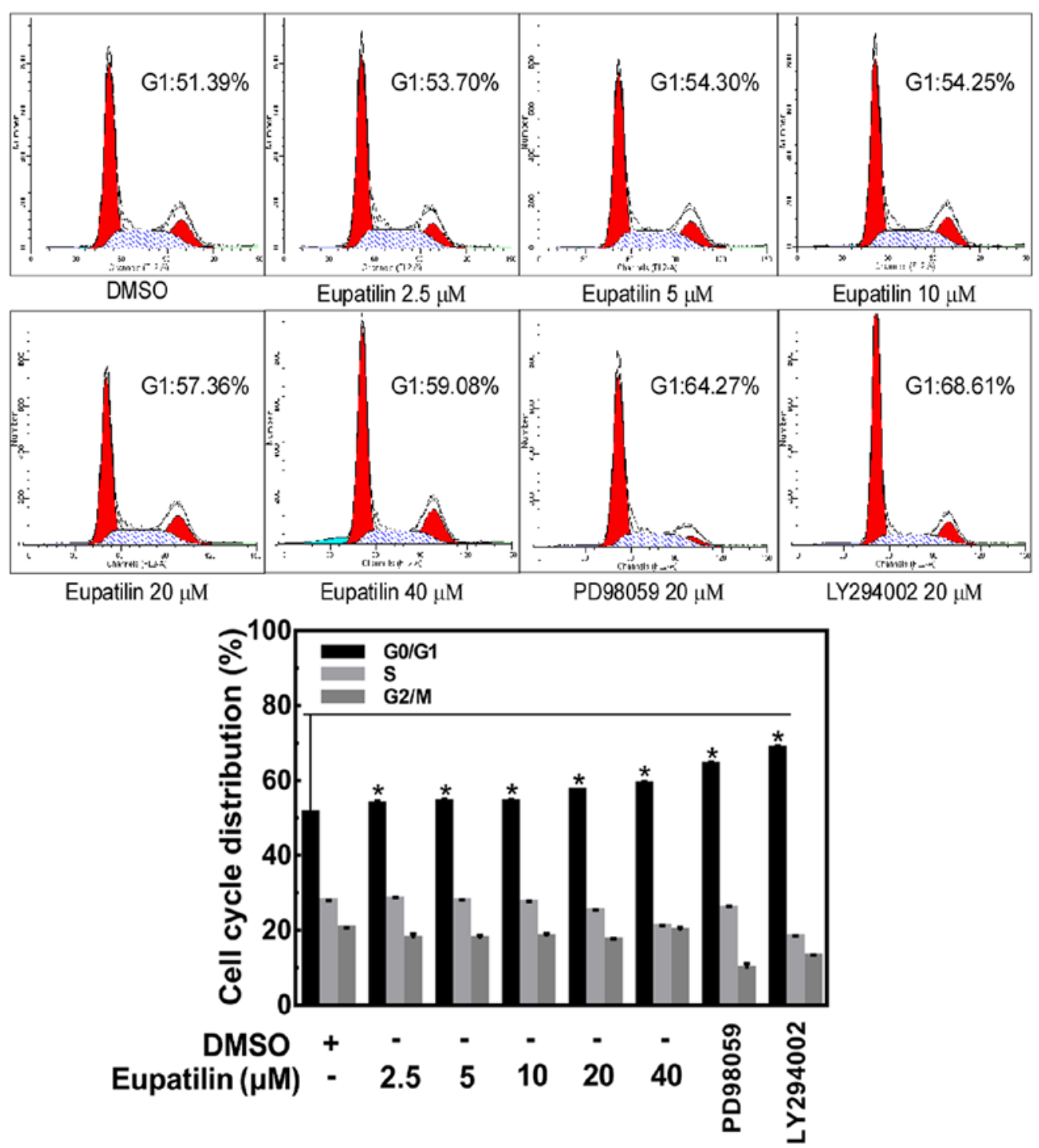

Figure 2. Eupatilin induces cell cycle arrest at $\mathrm{G}_{0} / \mathrm{G}_{1}$ phase. Cells were treated with the indicated concentrations of eupatilin, $20 \mu \mathrm{M}$ PD98059 or $20 \mu \mathrm{M}$ LY294002 for $24 \mathrm{~h}$, and cell cycle distribution was assessed by flow cytometric analysis with propidium iodide staining. The percentages of cells in the $\mathrm{G}_{1} / \mathrm{G}_{0}, \mathrm{~S}$ and $\mathrm{G}_{2} / \mathrm{M}$ phases are shown as means $\pm \mathrm{SD}$ from triplicate experiments. ${ }^{*} \mathrm{P}<0.05$, significant increase in $\mathrm{G}_{0} / \mathrm{G}_{1}$ phase cells in the treated group vs. the untreated group).
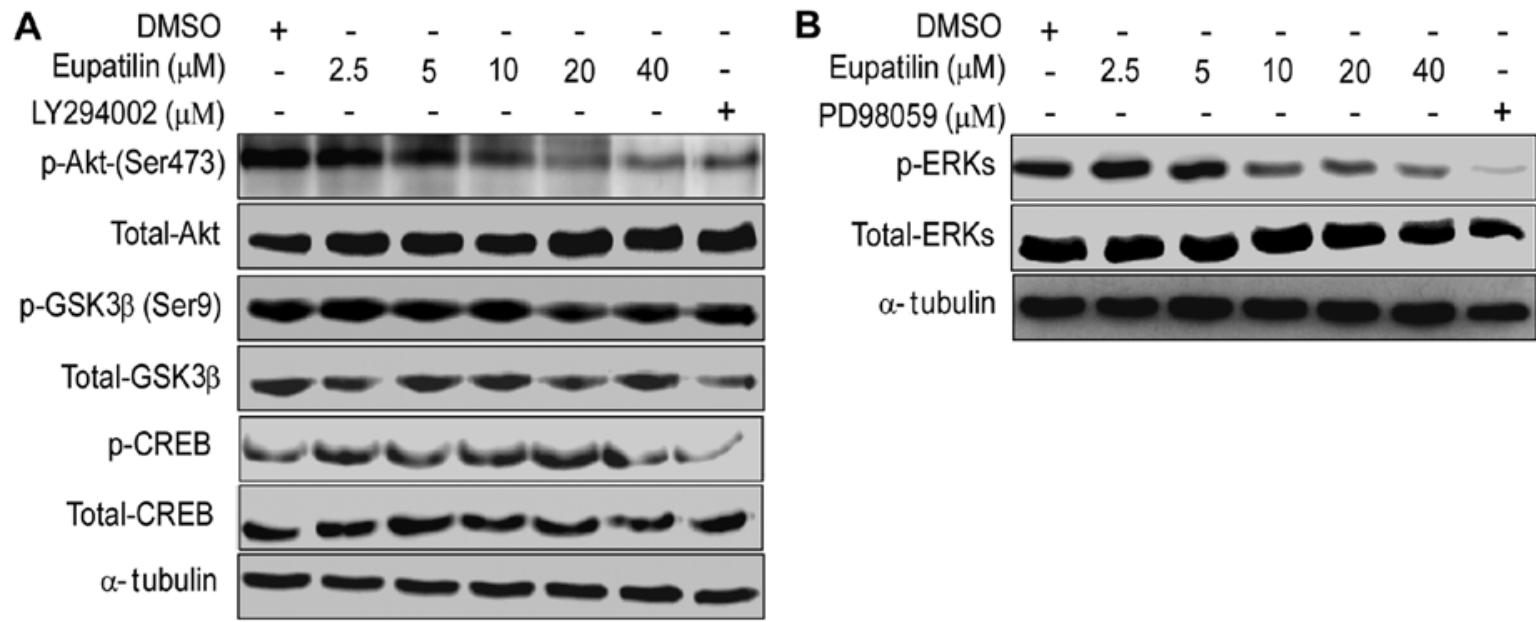

Figure 3. Eupatilin regulates the signaling pathways of Akt/GSK3 $\beta$ and MAPK/ERK. (A) Inhibitory effect of eupatilin on Akt-GSK3 $\beta$ signaling. TE1 cells were treated with eupatilin or LY294002 for $24 \mathrm{~h}$. Protein levels were detected by western blot analysis with specific primary antibodies as indicated. (B) Inhibitory effect of eupatilin on the MAKP/ERK pathway. TE1 cells were treated with eupatilin or PD98059 for 24 h. Protein levels were detected by western blot analysis with specific primary antibodies as indicated. 

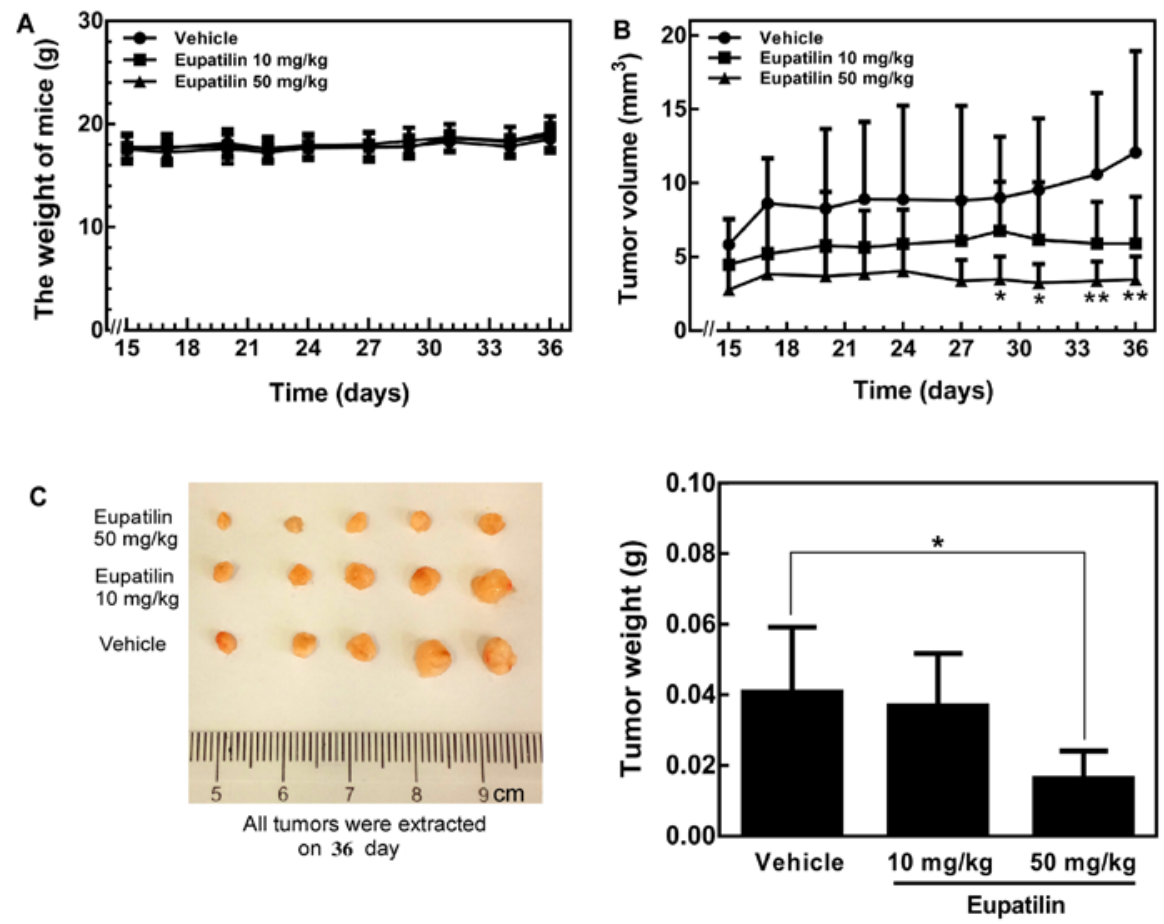

Figure 4. Eupatilin suppresses tumor growth in vivo. (A) Eupatilin had no effect on the body weight of the mice. All mice were weighed 3 times/week after injection of TE1 cells, and curves of mouse body weight were plotted. (B) Eupatilin reduces xenograft tumor volumes. Tumor volume in each mouse was measured with a caliper 3 times/week and tumor volume curves were plotted. (C) When the mice were sacrificed, the tumors were extracted and weighed. Representative images are shown $\left(\mathrm{C}\right.$, left panel). Bar graphs were drawn to compare the total average tumor weights $\left(\mathrm{C}\right.$, right panel) $\left({ }^{*} \mathrm{P}<0.05,{ }^{* *} \mathrm{P}<0.01\right.$, a significant decrease in tumor volume compared with the vehicle-treated control group).

The results indicated a modest decrease in tumor volume in the eupatilin-treated groups from the beginning to the end of the experiment (Fig. 4B). Additionally, the $50 \mathrm{mg} / \mathrm{kg}$ body weight eupatilin treatment caused significantly greater inhibition compared with the lower dose treatment $(10 \mathrm{mg} / \mathrm{kg}$ body weight) (Fig. 4B). At the end of the experiment, the mice were euthanized, the tumors were extracted and weighed, and these results were confirmed (Fig. 4C). Notably, the average tumor size in mice receiving $50 \mathrm{mg} / \mathrm{kg}$ eupatilin was significantly reduced compared with tumors in the eupatilin-untreated mice ( $\mathrm{P}<0.05$ vs. control). Meanwhile, in the $10 \mathrm{mg} / \mathrm{kg}$ eupatilin group, the average tumor volume was smaller than that in the eupatilin-untreated group without statistical significance (Fig. 4B). In addition, the body weights of all animals were monitored and remained stable during the experiment (Fig. 4A), which suggested that the doses of eupatilin used for the experiment were not severely toxic to the mice. In the early stage, we carried out the acute toxicity test of eupatilin in nude mice, and the maximum tolerated dose was $50 \mathrm{mg} / \mathrm{kg}$. When the dosage of the drug was higher than $50 \mathrm{mg} / \mathrm{kg}$, the mice exhibited bradykinesia and weight loss and the mental state was dispirited. When the dose reached $150 \mathrm{mg} / \mathrm{kg}$, the mice died overnight. In order to investigate whether eupatilin inhibits tumor in a dose-dependent manner, we also set up a low dose of $10 \mathrm{mg} / \mathrm{kg}$. Overall, these data indicate that eupatilin can inhibit tumor growth in vivo.

Eupatilin inhibits cell proliferation and Akt and ERK signaling in tumors. To assess whether eupatilin suppressed tumor growth in vivo by regulating the Akt and ERK signaling pathways, we first detected the expression of $\mathrm{Ki}-67$, a cellular biomarker of proliferation, in the xenograft tumor tissues using immunohistochemistry. We observed that $50 \mathrm{mg} / \mathrm{kg}$ eupatilin significantly inhibited Ki-67 expression compared with vehicle and $10 \mathrm{mg} / \mathrm{kg}$ eupatilin (Fig. 5A). Next, p-Akt and p-ERK were assessed by immunohistochemistry. We found that the levels of Akt phosphorylation (Ser473) and ERK phosphorylation in the $50 \mathrm{mg} / \mathrm{kg}$ eupatilin group were decreased compared with the vehicle group, while phosphorylation changes in the $10 \mathrm{mg} / \mathrm{kg}$ eupatilin group were observed to a lesser extent (Fig. 5B). Taken together, these data suggested that the inhibitory effect of eupatilin on tumor growth in the mouse model may be associated with the Akt and ERK signaling pathways.

\section{Discussion}

Both the incidence and mortality rates of esophageal cancer in Eastern Asia are high, particularly in China. When the disease is diagnosed, it is typically in the middle or late stage of the cancer. The traditional treatment methods for esophageal cancer are not reliable for improving prognosis. Thus, there is an urgent need to identify more useful methods that can prevent or treat the malignant cancer. Eupatilin, a flavone compound, has potential anticancer activity $(6,24)$. It has been reported that eupatilin induces human renal cancer cell apoptosis via ROS-mediated MAPK and PI3K/AKT signaling pathways (25). Epatilin is a potential chemopreventive agent in inhibition of skin cell transformation by targeting PI3K, and is independent of the ERK-related signaling pathway (ERK1/2, RSK2 and CREB) (24). However, to the best of our knowledge, no study has explored the effect of eupatilin on human esophageal cancer cells. Specifically, the antitumor effects include 

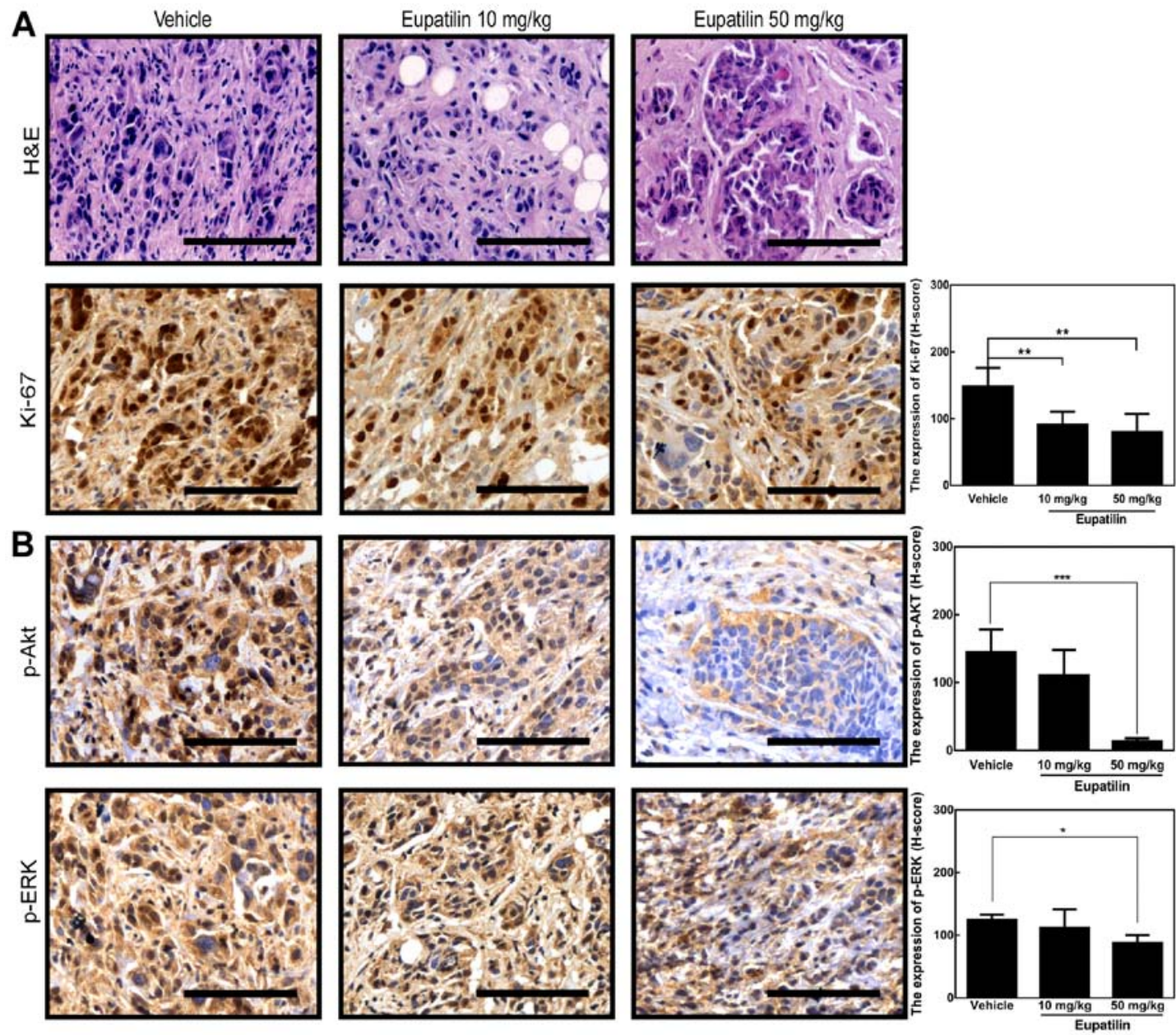

Figure 5. Eupatilin suppresses cell proliferation and phosphorylation of Akt and ERK in the xenograft mouse model. (A) Eupatilin inhibited Ki-67 expression in the xenograft tumors. Histological sections were stained with hematoxylin and eosin (H\&E) and the expression of Ki-67 was detected by immunohistochemistry analysis. Representative images of each group are shown. The staining of Ki-67 was analyzed using HistoQuest 4.0 software and evaluated using the H-Score system. The asterisks indicate a significant decrease compared with the vehicle-treated control group ("* $\mathrm{P}<0.01)$. (B) The phosphorylation levels of Akt and ERK were detected by immunohistochemistry analysis. Representative images of each group are shown. The staining of p-Akt and p-ERK was analyzed using HistoQuest 4.0 software and evaluated by H-Score. The asterisks indicate a significant decrease compared with the vehicle-treated control group $\left({ }^{*} \mathrm{P}<0.05,{ }^{* * *} \mathrm{P}<0.0001\right)($ Scale bar, $100 \mu \mathrm{M})$.

inhibition of human esophageal cancer cell proliferation and promotion of apoptosis in vivo has rarely been investigated. Accordingly, in the present study, we confirmed the antiproliferative effect of eupatilin in human esophageal cancer cells not only in vitro but also in vivo. To further investigate whether eupatilin can suppress tumor growth in vivo, we evaluated the antitumor activity of eupatilin in athymic nude mice implanted with human esophageal cancer cells. Obviously, we found that the high dose of eupatilin $(50 \mathrm{mg} / \mathrm{kg}$ body weight) strongly suppressed tumor growth. In addition, we confirmed that eupatilin suppressed the anchorage-independent growth of esophageal cancer cells, which can reflect the extent of malignancy in part. In the present study, we partially identified the mechanism by which eupatilin may inhibit the proliferation of esophageal cancer TE1 cells. The results showed that the percentage of viable TE1 cells was reduced to $80 \%$ following treatment with $3.125 \mu \mathrm{M}$ eupatilin for $48 \mathrm{~h}$ (Fig. 1B). This indicated that eupatilin has a significant antiproliferation effect on human esophageal cancer at very low concentrations. With the increase in the concentration of eupatilin, the antiproliferation effect had an increasing trend.
Uncontrolled cell proliferation is a typical characteristic of cancer cells. The MEK/MAPK pathway plays a significant role in the growth and survival of cancer cells $(26,27)$. When MAPK/ERK signaling is activated by certain stimuli, p-ERK enters the cell nucleus, which results in excessive cell proliferation, aggressive transformation and tumor progression, through the activation of various oncogenes. Studies have demonstrated that some natural plant ingredients or small synthetic molecules can inhibit cancer cell growth. For instance, curcumin inhibits cell proliferation in a time- and dose-dependent manner in human leukemia THP-1 cells by acting on the Akt/mTOR and RAF/MEK/ERK signaling pathways (28). In the present study, eupatilin inhibited the proliferation and anchorage-independent growth of TE1 cells (Fig. 1). Meanwhile, activation of Akt and MAPK/ERK were decreased by eupatilin in the TE1 cells, which had the same results as treatment with LY294002 or PD98059, which are known to be inhibitors of the PI3K/Akt and ERK pathways, respectively (Fig. 3). We observed that the treatments with different concentrations of eupatilin in TE1 cells for $24 \mathrm{~h}$ may cause decreases in the levels of p-CREB (Fig. 3). As known, CREB activity is regulated by phosphorylation 
at Ser133, which is a target of various kinases depending on the specific signaling stimulus and cell type $(29,30)$. CREB is a validated phosphorylated substrate of ERK, PKA, and $\mathrm{Ca}^{2+} /$ calmodulin-dependent protein kinases (31). Akt activation can sequentially activate the downstream mTOR complex 1 (mTORC1) and GSK3 $\beta$, both of which play important roles in cancer development (29). GSK-3 activity promotes conditional association of CREB $(32,33)$. CREB is a transcription factor involved in various biological processes, including cancer, whose activity is promoted by GSK-3 phosphorylation (34). In the present study, treatment with eupatilin, as well as LY294002, caused significant decreases in the levels of p-Akt, p-GSK3 $\beta$ and p-CREB. When the Akt-GSK3 $\beta$ signaling pathway is blocked, it causes decreases in the levels of p-CREB. At the same time, CREB is a validated phosphorylated substrate of ERK (31). MAPK/ERK is involved in indirect regulation of CREB via activation of MSK1 (30). The present study found that the antiproliferative effect of eupatilin was facilitated by targeting the Akt/GSK3 $\beta$ and MAPK/ERK signaling pathways. When the MAPK/ERK signaling pathway is blocked, it probably causes decreases in the levels of p-CREB. Taken together, the present study suggests that both the Akt/GSK3 $\beta$ and MAPK/ERK signaling pathways may cause decreases in the levels of $\mathrm{p}$-CREB.

Components of the MAPK and PI3K signaling pathways are mediated by receptor tyrosine kinases in esophageal cancer (35). Upon stimulation by growth factors, cytokines and physical factors, PI3K is activated, and Akt becomes phosphorylated. Researchers have found that Akt activation promotes cell proliferation through multiple downstream targets (GSK3 $\beta$, for instance) that affect the cell cycle (36). Moreover, the MEK/ERK pathway also participates in the regulation of cyclin D1 expression (21). In the present study, we found that eupatilin induced cell cycle arrest at the $G_{0} / G_{1}$ phase, which was associated with eupatilin-mediated inhibition of the Akt/GSK3 $\beta$ and ERK pathways (Figs. 2 and 3). Our previous study demonstrated that eupatilin induced cell cycle arrest at the $\mathrm{G}_{0} / \mathrm{G}_{1}$ phase by inhibiting the activity of cyclin D1 in EGF-treated JB6 cells (24). However, $\mathrm{G}_{2} / \mathrm{M}$ arrest of the cell cycle has been observed in eupatilin-treated human endometrial carcinoma Hec1A cells (37). This difference between $\mathrm{G}_{0} / \mathrm{G}_{1}$ and $\mathrm{G}_{2} / \mathrm{M}$ arrest may be determined by differences in signaling responses in different cell types, in cellular state, and in the environment at the time of eupatilin treatment.

Molecular-targeted therapy for tumors has made substantial progress, and new molecular-targeted drugs have exhibited efficacy in clinical practice $(38,39)$. The epidermal growth factor receptor (EGFR) signaling pathway plays important roles in tumor proliferation, survival and metastasis, among other processes $(19-22,40)$. Activation of EGFR can promote multiple intracellular signaling cascades involved in tumor growth, and thus these signaling molecules have been focused on as targets for cancer therapy. Raf/MEK/MAPK and PI3K/Akt/PTEN/mTOR are both downstream signaling pathways of EGFR. ERK and Akt can regulate cell cycle-related proteins, which generally results in cell growth and proliferation $(41,42)$. In our xenograft mouse model in the present study, we found that the higher dose of eupatilin $(50 \mathrm{mg} / \mathrm{kg}$ body weight) strongly suppressed tumor growth (Fig. 4B and C). Meanwhile, phosphorylation of Akt and ERK were suppressed in the high-dose eupatilin treatment group compared with the vehicle or low-dose eupatilin $(10 \mathrm{mg} / \mathrm{kg}$ body weight) treatment groups (Fig. 5). These findings indicated that eupatilin regulated the Akt and ERK pathways to inhibit tumor growth.

In conclusion, eupatilin suppressed the proliferation of esophageal cancer TE1 cells, cause cell cycle arrest at $\mathrm{G}_{0} / \mathrm{G}_{1}$ phase, and suppressed TE1 xenograft tumor growth by decreasing activation of the Akt and MAPK/ERK signaling pathways. In future studies, we aim to explore the underlying mechanisms in more detail to identify the potential targets of eupatilin in the two pathways, in order to determine possible therapeutic targets in esophageal cancer.

\section{Acknowledgements}

Not applicable.

\section{Funding}

The present study was supported by the National Natural Science Foundation of China (grant nos. 81372269, 81472324 and 81572812) and the Science Foundation of Henan Education Department (grant no. 14A310011).

\section{Availability of data and materials}

The datasets used during the present study are available from the corresponding author upon reasonable request.

\section{Authors' contributions}

JiZ, KL, XW and YZhu conceived and designed the study. XW, YZhu, LZ, YZhao, YS, XChen, YX, FL and YJ performed the experiments. JL, YH, XChang, JuZ, XL, KL, MZ and ZD helped perform the data analyses and interpreted the results. All authors read and approved the manuscript and agree to be accountable for all aspects of the research in ensuring that the accuracy or integrity of any part of the work are appropriately investigated and resolved.

\section{Ethics approval and consent to participate}

All animal studies conformed to guidelines approved by the Research Ethics Committee of Zhengzhou University (Zhengzhou, Henan, China).

\section{Consent for publication}

Not applicable.

\section{Competing interests}

The authors state that they have no competing interests.

\section{References}

1. Pennathur A, Gibson MK, Jobe BA and Luketich JD: Oesophageal carcinoma. Lancet 381: 400-412, 2013.

2. Xiao Z, Peng Z, Peng M, Yan W, Ouyang Y and Zhu H: Flavonoids health benefits and their molecular mechanism. Mini Rev Med Chem 11: 169-177, 2011. 
3. Li ZG, Shimada Y, Sato F, Maeda M, Itami A, Kaganoi J, Komoto I, Kawabe A and Imamura M: Inhibitory effects of epigallocatechin-3-gallate on $\mathrm{N}$-nitrosomethylbenzylamine-induced esophageal tumorigenesis in F344 rats. Int J Oncol 21: 1275-1283, 2002.

4. Kumar S and Pandey AK: Chemistry and biological activities of flavonoids: An overview. ScientificWorldJournal 2013: 162750 , 2013.

5. Ye F, Zhang GH, Guan BX and Xu XC: Suppression of esophageal cancer cell growth using curcumin, (-)-epigallocatechin-3-gallate and lovastatin. World J Gastroenterol 18: 126-135, 2012.

6. Kim MJ, Kim DH, Na HK, Oh TY, Shin CY and Surh Ph D Professor YJ: Eupatilin, a pharmacologically active flavone derived from Artemisia plants, induces apoptosis in human gastric cancer (AGS) cells. J Environ Pathol Toxicol Oncol 24: 261-269, 2005

7. Seo HJ, Park KK, Han SS, Chung WY, Son MW, Kim WB and Surh YJ: Inhibitory effects of the standardized extract (DA-9601) of Artemisia asiatica Nakai on phorbol ester-induced ornithine decarboxylase activity, papilloma formation, cyclooxygenase-2 expression, inducible nitric oxide synthase expression and nuclear transcription factor kappa B activation in mouse skin. Int J Cancer 100: 456-462, 2002.

8. Min SW, Kim NJ, Baek NI and Kim DH: Inhibitory effect of eupatilin and jaceosidin isolated from Artemisia princeps on carrageenan-induced inflammation in mice. $\mathrm{J}$ Ethnopharmacol 125: 497-500, 2009.

9. Yun C, Jung Y, Chun W, Yang B, Ryu J, Lim C, Kim JH, Kim H and Cho SI: Anti-inflammatory effects of Artemisia leaf extract in mice with contact dermatitis in vitro and in vivo. Mediators Inflamm 2016: 8027537, 2016.

10. Wang Y, Hou H, Li M, Yang Y and Sun L: Anticancer effect of eupatilin on glioma cells through inhibition of the Notch-1 signaling pathway. Mol Med Rep 13: 1141-1146, 2016.

11. Steelman LS, Chappell WH, Abrams SL, Kempf RC, Long J, Laidler P, Mijatovic S, Maksimovic-Ivanic D, Stivala F, Mazzarino MC, et al: Roles of the Raf/MEK/ERK and $\mathrm{PI} 3 \mathrm{~K} / \mathrm{PTEN} / \mathrm{Akt} / \mathrm{mTOR}$ pathways in controlling growth and sensitivity to therapy-implications for cancer and aging. Aging (Albany NY) 3: 192-222, 2011

12. Sewing A, Wiseman B, Lloyd AC and Land H: High-intensity Raf signal causes cell cycle arrest mediated by p21Cip1. Mol Cell Biol 17: 5588-5597, 1997.

13. Woods D, Parry D, Cherwinski H, Bosch E, Lees E and McMahon M: Raf-induced proliferation or cell cycle arrest is determined by the level of Raf activity with arrest mediated by p21Cip1. Mol Cell Biol 17: 5598-5611, 1997.

14. Knauf JA, Sartor MA, Medvedovic M, Lundsmith E, Ryder M Salzano M, Nikiforov YE, Giordano TJ, Ghossein RA and Fagin JA: Progression of BRAF-induced thyroid cancer is associated with epithelial-mesenchymal transition requiring concomitant MAP kinase and TGF $\beta$ signaling. Oncogene 30: 3153-3162, 2011

15. Clair T, Miller WR and Cho-Chung YS: Prognostic significance of the expression of a ras protein with a molecular weight of 21,000 by human breast cancer. Cancer Res 47: 5290-5293, 1987.

16. Janes PW, Daly RJ, deFazio A and Sutherland RL: Activation of the Ras signalling pathway in human breast cancer cells overexpressing erbB-2. Oncogene 9: 3601-3608, 1994.

17. Bos JL: Ras oncogenes in human cancer: A review. Cancer Res 49: 4682-4689, 1989.

18. Wee P and Wang Z: Epidermal growth factor receptor cell proliferation signaling pathways. Cancers (Basel) 9: 2017.

19. Kaul R, Saha P, Saradhi M, Prasad RL, Chatterjee S, Ghosh I, Tyagi RK and Datta K: Overexpression of hyaluronan-binding protein 1 (HABP1/p32/gClqR) in HepG2 cells leads to increased hyaluronan synthesis and cell proliferation by up-regulation of cyclin D1 in AKT-dependent pathway. J Biol Chem 287: 19750-19764, 2012.

20. Lv C, Qin W, Zhu T, Wei S, Hong K, Zhu W, Chen R and Huang C: Ophiobolin O isolated from Aspergillus ustus induces G1 arrest of MCF-7 cells through interaction with AKT/GSK3 $3 /$ cyclin D1 signaling. Mar Drugs 13: 431-443, 2015.

21. Wang HY, Yang SL, Liang HF and Li CH: HBx protein promotes oval cell proliferation by up-regulation of cyclin D1 via activation of the MEK/ERK and PI3K/Akt pathways. Int J Mol Sci 15 $3507-3518,2014$

22. Thompson KN, Whipple RA, Yoon JR, Lipsky M, Charpentier MS, Boggs AE, Chakrabarti KR, Bhandary L, Hessler LK, Martin SS and Vitolo MI: The combinatorial activation of the PI3K and Ras/MAPK pathways is sufficient for aggressive tumor formation, while individual pathway activation supports cell persistence. Oncotarget 6: 35231-35246, 2015
23. Bode AM and Dong Z: Signal transduction and molecular targets of selected flavonoids. Antioxid Redox Signal 19: 163-180, 2013.

24. Li F, Tao Y, Qiao Y, Li K, Jiang Y, Cao C, Ren S, Chang X, Wang X, Wang Y, et al: Eupatilin inhibits EGF-induced JB6 cell transformation by targeting PI3K. Int J Oncol 49: 1148-1154, 2016.

25. Zhong WF, Wang XH, Pan B, Li F, Kuang L and Su ZX: Eupatilin induces human renal cancer cell apoptosis via ROS-mediated MAPK and PI3K/AKT signaling pathways. Oncol Lett 12: 2894-2899, 2016

26. Blackhall FH, Pintilie M, Michael M, Leighl N, Feld R, Tsao MS and Shepherd FA: Expression and prognostic significance of kit, protein kinase $\mathrm{B}$, and mitogen-activated protein kinase in patients with small cell lung cancer. Clin Cancer Res 9: 2241-2247, 2003.

27. Huynh H, Nguyen TT, Chow KH, Tan PH, Soo KC and Tran E: Over-expression of the mitogen-activated protein kinase (MAPK) kinase (MEK)-MAPK in hepatocellular carcinoma: Its role in tumor progression and apoptosis. BMC Gastroenterol 3 : 19, 2003.

28. Guo Y, Shan Q, Gong Y, Lin J, Shi F, Shi R and Yang X: Curcumin induces apoptosis via simultaneously targeting AKT/mTOR and RAF/MEK/ERK survival signaling pathways in human leukemia THP-1 cells. Pharmazie 69: 229-233, 2014.

29. de Groot RP, Ballou LM and Sassone-Corsi P: Positive regulation of the CAMP-responsive activator CREM by the p70 S6 kinase: An alternative route to mitogen-induced gene expression. Cell 79: 81-91, 1994.

30. Xing J, Ginty DD and Greenberg ME: Coupling of the RAS-MAPK pathway to gene activation by RSK2, a growth factor-regulated CREB kinase. Science 273: 959-963, 1996.

31. Tan Y, Rouse J, Zhang A, Cariati S, Cohen P and Comb MJ: FGF and stress regulate CREB and ATF-1 via a pathway involving p38 MAP kinase and MAPKAP kinase-2. EMBO J 15: 4629-4642, 1996.

32. Fiol CJ, Williams JS, Chou CH, Wang QM, Roach PJ and Andrisani OM: A secondary phosphorylation of CREB341 at Ser129 is required for the cAMP-mediated control of gene expression. A role for glycogen synthase kinase-3 in the control of gene expression. J Biol Chem 23: 32187-32193, 1994.

33. Wang Z, Iwasaki M, Ficara F, Lin C, Matheny C, Wong SH, Smith KS and Cleary ML: GSK-3 promotes conditional association of CREB and its coactivators with MEIS1 to facilitate HOX-mediated transcription and oncogenesis. Cancer Cell 17: 597-608, 2010

34. Horike N, Sakoda H, Kushiyama A, Ono H, Fujishiro M, Kamata H, Nishiyama K, Uchijima Y, Kurihara Y, Kurihara H and Asano T: AMP-activated protein kinase activation increases phosphorylation of glycogen synthase kinase 3beta and thereby reduces cAMP-responsive element transcriptional activity and phosphoenolpyruvate carboxykinase $\mathrm{C}$ gene expression in the liver. J Biol Chem 283: 33902-33910, 2008.

35. Lin DC, Hao JJ, Nagata Y, Xu L, Shang L, Meng X, Sato Y, Okuno Y, Varela AM, Ding LW, et al: Genomic and molecular characterization of esophageal squamous cell carcinoma. Nat Genet 46: 467-473, 2014.

36. Manning BD and Cantley LC: AKT/PKB signaling: Navigating downstream. Cell 129: 1261-1274, 2007.

37. Cho JH, Lee JG, Yang YI, Kim JH, Ahn JH, Baek NI, Lee KT and Choi JH: Eupatilin, a dietary flavonoid, induces G2/M cell cycle arrest in human endometrial cancer cells. Food Chem Toxicol 49: 1737-1744, 2011.

38. Li K and Li J: Current molecular targeted therapy in advanced gastric cancer: A comprehensive review of therapeutic mechanism, clinical trials, and practical application. Gastroenterol Res Pract 2016: 4105615, 2016.

39. Wang H, Xu T, Jiang Y, Xu H, Yan Y, Fu D and Chen J: The challenges and the promise of molecular targeted therapy in malignant gliomas. Neoplasia 17: 239-255, 2015.

40. Borlak J, Meier T, Halter R, Spanel R and Spanel-Borowski K: Epidermal growth factor-induced hepatocellular carcinoma: Gene expression profiles in precursor lesions, early stage and solitary tumours. Oncogene 24: 1809-1819, 2005.

41. Adlung L, Kar S, Wagner MC, She B, Chakraborty S, Bao J, Lattermann S, Boerries M, Busch H, Wuchter P, et al: Protein abundance of AKT and ERK pathway components governs cell type-specific regulation of proliferation. Mol Syst Biol 13: 904, 2017.

42. Saez-Rodriguez J, MacNamara A and Cook S: Modeling signaling networks to advance new cancer therapies. Annu Rev Biomed Eng 17: 143-163, 2015. 